
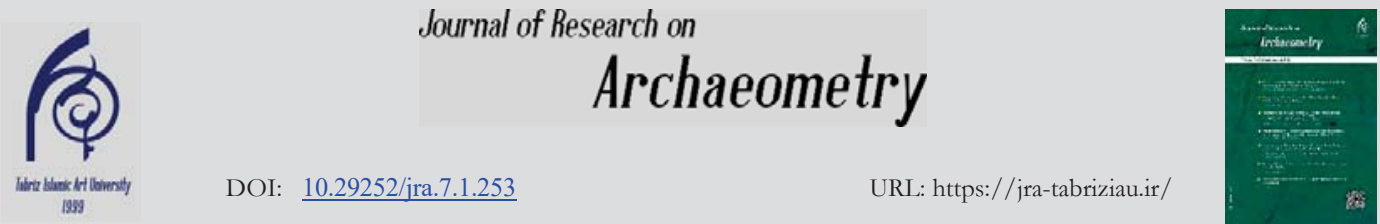

Original Paper

\title{
Investigating Numerical Sequences in Decagona Geometric Ornamentation
}

\author{
Majid Heydari Delgarm ${ }^{1 *}$, Mahdi Barqzadegan², \\ 1. Assistant Professor, Department of Architecture, Bu-Ali Sina University, Hamedan, IRAN \\ 2. M.A. in Architecture, Islamic Azad University, Hamedan Branch, IRAN
}

Received: 29/04/2021

Accepted: $21 / 08 / 2021$

\begin{abstract}
This paper aims to introduce a previously unknown feature of a family of girih designs. This research is seeking to answer the question that "With what mathematical pattern does subdividing girih goes on?" Results show that in repeatedly subdividing girih, by maintaining the size of the polygons, frames grows in a sequence with properties of a generalization of Fibonacci. Some realworld samples, that are put together, show the same properties. This feature could in the future be used to design and analyze girihs. These applications are discussed in the latter sections of the paper.

Keywords: Geometry in Architecture, Decagonal Girih, Fibonacci Sequence, Golden ratio.

\section{Introduction}

In this paper, a mathematical feature of girih is explained. Girih is a type of geometric design in Islamic art that can be distinguished from calligraphy and vegetal ornaments [6]. It is composed of several polygons filling the surface area of a frame. There is rich literature on girih and Mathematical analysis of Girih is a significant part of this literature.

The literature focusing on girih can be divided into two types of major sources. The first is educational mostly written by master builders of architecture and their apprentices [1-4]. They are meant to teach the traditional methods of designing and drafting girih. The second type is investigative, mostly carried out by academicians. These sources investigate historic, aesthetic, or mathematical, as well as other aspects of Girih. A portion of research has focused on mathematical features of girih design including geometric and numerical. These can be traced back to Bourgoin's work [5]. Academic writings continued in the 20th century, and in the 21 st century, a paper by Lu and Steinhardt [22] opened new discussions on the subject. The paper focused on decagonal Girih.
\end{abstract}

\section{Materials and Methods}

Several methods have been used or proposed to categorize Girih designs. A criterion is symmetry group and base regular polygons. Since the only regular polygons that can fill a flat surface are equilateral triangles, squares, and hexagons, but not the pentagons, there is a fundamental difference between the five-fold (decagonal) design and the other three. Five-fold designs are sometimes associated with eastern parts of the Islamic world [13]. In some of the sources authored by Iranian master builders (e.g. Lurzādah, Sha 'rbāf ), some controlling rules are mentioned for designing. Fig. 1 shows a set of five polygons that can be used together to fill a surface. the set belongs to a decagonal design called Kund-i dah (meaning obtuse/blunt ten).

*Corresponding Author: Heydaridelgarm@basu.ac.ir

Copyright $@ 2021$, the Authors / This open-access article is published under the terms of the Creative Commons Attribution-NonCommercial 4.0 International License which permits Share (copy and redistribute the material in any medium or format) and Adapt (remix, transform, and build upon the material) under the Attribution-NonCommercial .terms 
Designs using this set can be subdivided. Subdividing is converting polygons to similar smaller polygons that fill the same frame. The corresponding polygons in the subdivided frame are smaller than the original one. There are several

methods for subdividing and in this paper one introduced by apprentices of Lurzādah a master of Iranian architecture is used [21].

\section{Results}

The girih-i kund-i dah which uses the polygons introduced in Fig. 1 can be subdivided to make new designs but with smaller polygons. This has been known by master builders and is introduced in their texts. The most basic Girih pattern introduced in these sources (which has an easy method for drafting) is called ūmm al-girih (meaning mother of knots) since subdividing it results in new designs. The method Lurzādah has introduced for subdividing could be used repeatedly. (Fig. 2) His two apprentices, Ra'̄̄szādah and Mufīd have applied the method four times in a row on a design, but it is not limited to 4 [21]. In decagonal designs, the underlying grid would change by subdividing. This means that there is not necessarily a "combining" action in the opposite direction of subdividing to make a pre-subdivision design. In this paper, it is shown that subdividing is related to the golden ratio and generalization of the Fibonacci sequence. The two concepts are defined below:

$\mathrm{a}$ and $\mathrm{b}$ are in the golden ratio if this equation is true

$\frac{b}{a}=\frac{a}{a+b}$

The value of this ratio is also the result of the equation:

$\varphi=\frac{1+\sqrt{5}}{2}$

The golden ratio is an irrational number that is approximately equal to 1.618. Its value to the power of two is one unit larger than itself.

$\varphi^{2}=\varphi+1$

This ratio could be shown geometrically in different shapes. The length of a diagonal of a regular pentagon with the side length of one unit is equal to the golden ratio. This relates the ratio to the Fibonacci sequence. Fibonacci introduced his famous sequence in the $13^{\text {th }}$ century [30].

In the first step, a decagonal as shown in fig. 2 was subdivided several times. In subdividing by this method similar polygons in the resulting designs would be scaled by reciprocal of phi $\left(\frac{1}{\varphi}\right)$. Since the designs have frames of the same size, by scaling each design by a factor that equates corresponding polygons of different designs, the frames too would be scaled by that factor. Fig. $3 \mathrm{~b}$ and $3 \mathrm{c}$ show this scaling. Each frame is $\varphi$ times its previous one. If the length of one of the sides of the first frame is equal to one unit, then along with the lengths of its corresponding sides in the next frames after scaling be listed as a sequence, it would form a geometric progression with common ratio $\varphi$. In this sequence, each term (after the second one) is the sum of the two previous terms.

There are examples of self-similar Girih designs (subdivisions of a large scale design by smaller polygons) in real-world in different buildings. Some of their parts could be chosen and put together to show the same result as shown in Fig.4. The sequence was continued by the authors. The theorem was also tested in an approximately 11 by 8 units rectangle. Fig. 5 shows each length of a rectangle is equal to the sum of the two previous ones:

$l_{n+2}=l_{n}+l_{n+1}$

This is also true for widths. In Fig. 5 the sides of the rectangles (except for the first rectangle) are axes of symmetry for small scale polygons.

\section{Discussion}

By subdividing the design, the ratio of the side-lengths of the frame to side-lengths of polygons changes by the golden ratio. The frames could be arranged in a spiral that shows their relation to the generalization of the Fibonacci sequence. These arise from the relation between decagonal designs and the golden ratio which itself is because they are based on pentagons. A diagonal of a pentagon is in extreme and mean (golden) ratio to its sides. As there are pentagons in these designs it could be shown that the side length of pentagons before subdividing is equal to the size of the 
diagonal of the pentagon after subdividing. This is shown in Fig. 6. Since all polygons are scaled proportionally, the scale factor is equal for all the polygons within a frame.

By scaling frames by a factor that results in corresponding polygons of the same size, the difference is displayed in frame sides' length. And since the ratio of the corresponding side length of each frame to its previous one is equal to phi a sequence for the scale factor of each member is as follows:

$G_{1}=\left\{\varphi^{0}, \varphi^{1}, \varphi^{2}, \varphi^{3}, \varphi^{4}, \varphi^{5}, \varphi^{6}, \varphi^{7}, \ldots\right\}$

And since

$\varphi^{2}=\varphi+1$

$G_{1}$ is equal to $G_{2}$

$G_{2}=\{1, \varphi, \varphi+1,2 \varphi+1,3 \varphi+2,5 \varphi+3,8 \varphi+5, \ldots\}$

As apparent $G_{2}$ is a generalization of the Fibonacci sequence, in which, after the first two terms, which are 1 and $\varphi$ each term is the sum of the two preceding ones.

\section{Conclusion}

One of the problems of geometric analysis and designing Girih for a specified frame is defining the size of the polygons. The relation between the size of the frame and the polygons for new designs can be calculated based on an existing design. In future research, such calculations can be used in analyzing and developing algorithmic solutions for designing. 


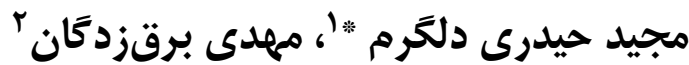

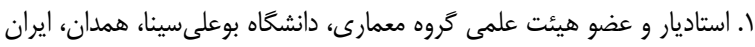

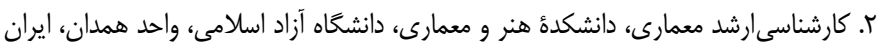

كره در كنار كتيبه و نقوش اسليمى سه دستأ اصلى تزئينات در معمارى اسلامى بوده است. اين آرايسهها در دو دسـتهٔ اصـلى منـابع

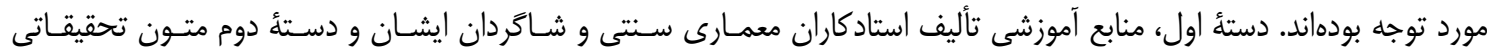

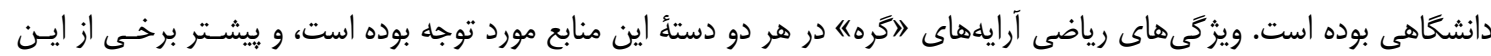

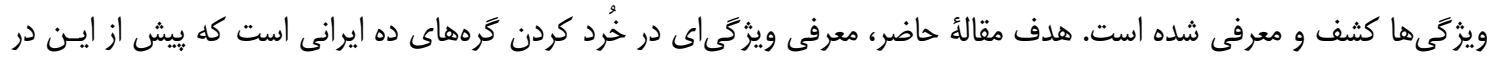

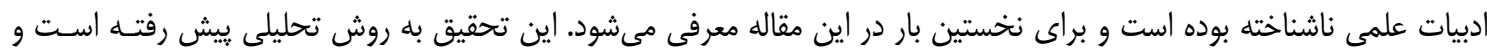

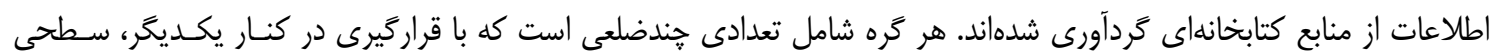

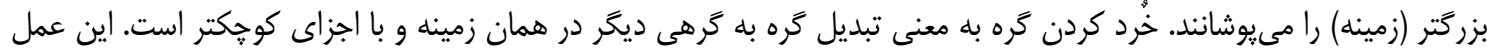

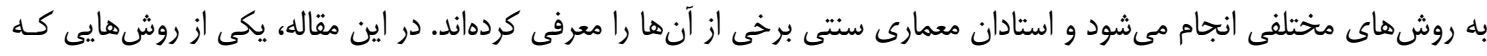

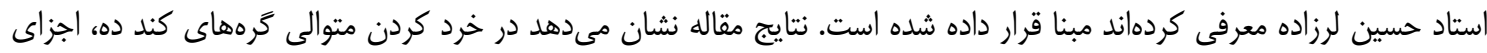

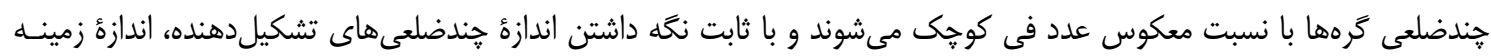

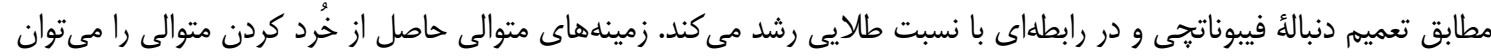

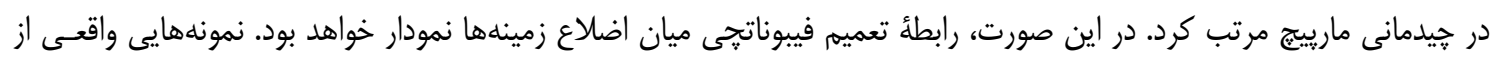

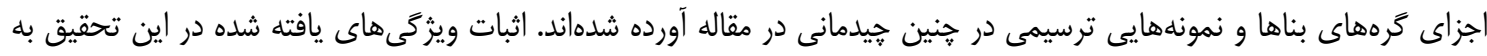

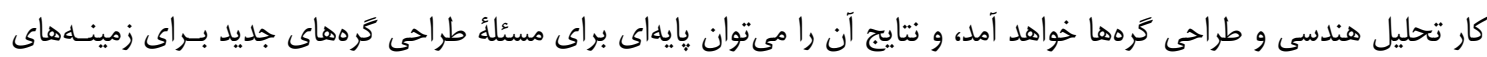
مختلف قرار داد.

وازَّان كليدى: هندسه در معمارى، گره كند ده، دنبالهُ فيبوناتجى، نسبت طلايى

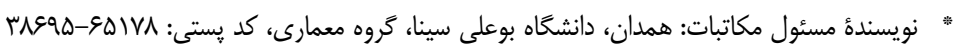

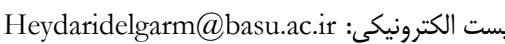

Creative Commons Attribution License حق نشر متعلق به نويسنده(كان) است و نويسنده تحت مجله اجازه مىدهد مقاله خاب شده را با ديخران به اشتراى بخذارد منوط بر اينكه حقوق مؤلف اثر حفظ و به انتشار اوليه مقاله در اين مجله اشاره شود. 


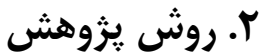

براى ييشبردن اين تحقيق، نمونههايى از گرههاى كند

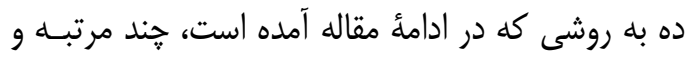
با اعمال هندسى خرد شد. سبِ روابـط رياضى ميــان

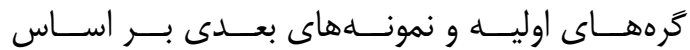

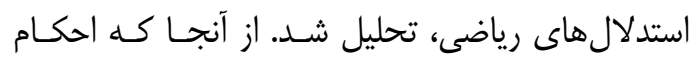

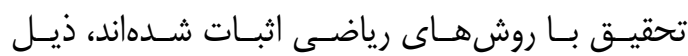
استدلال منطقى (Deduction) و در دسـتأه روشهـاى أنساي

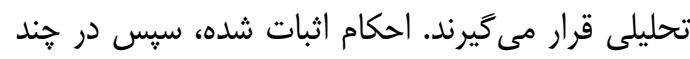

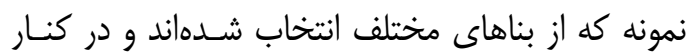

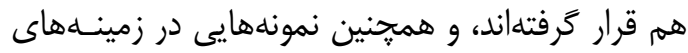
مستطيلى نمايش داده شدهاند. براى انتخـاب نمونـهـها،

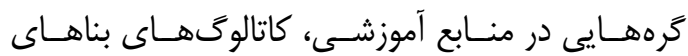
معمارى، بانكهاى اطلاعاتى كه شامل تصاوير كَره نيز

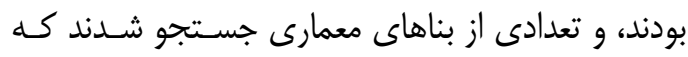
اين جستجو به سه نمونهاى كه در مقاله به آنها آنساري آنساره شده است، منتج شد. انتخاب اين نمونهها جنبئ آمـارى

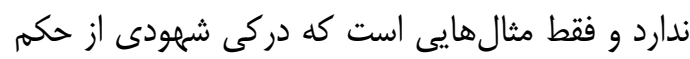

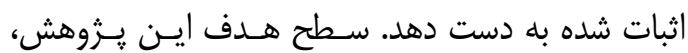
توسعهاى است و براى ياسخ به سئوال اصـلى تحقيـق، روشهاى ترسيه و خرد كردن گره از منابع كتابخانهاى جمع آورى شده است.

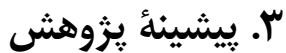

نوشتهاى متأخر دربارة نقوش هندسى در عالم اسلامى

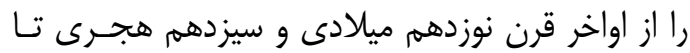

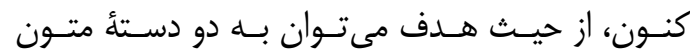

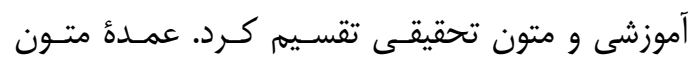
آموزشى را استادكاران معمارى و درودگرى يا شـاكَ دان

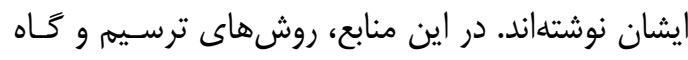

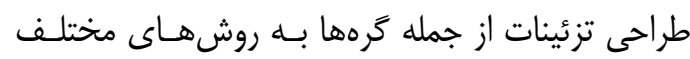

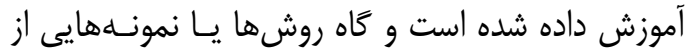

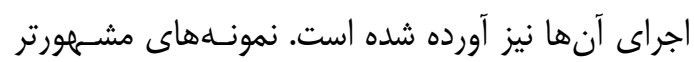

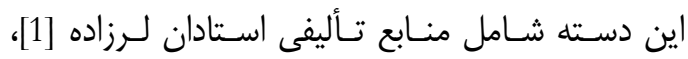
شعرباف [2]، زمرشيدى [3] و ماهر النقش [4] است.

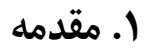

كره' (تزئينات هندسى) در كنار كتيبه و اسليمى يكى از

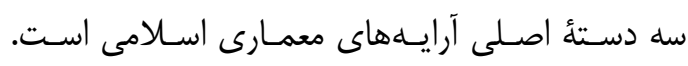

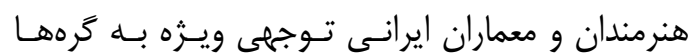

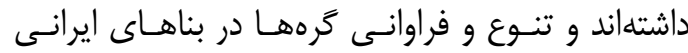

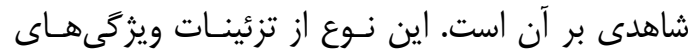

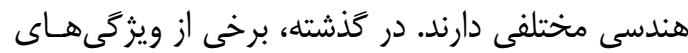

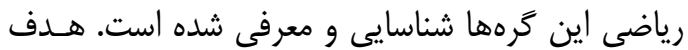

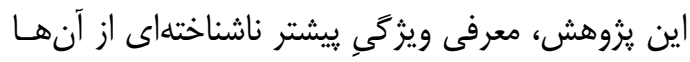

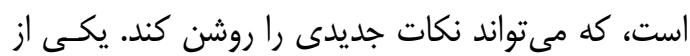

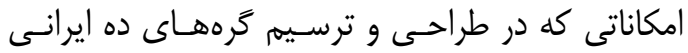

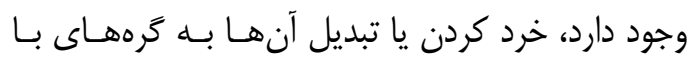

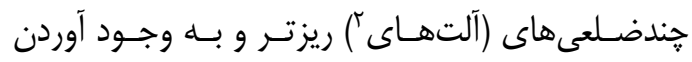

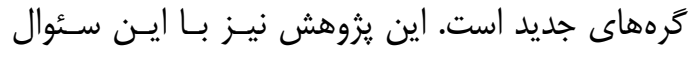

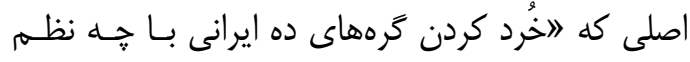

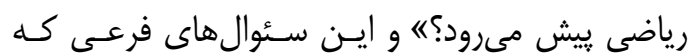

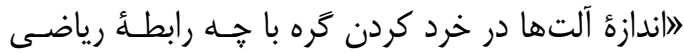

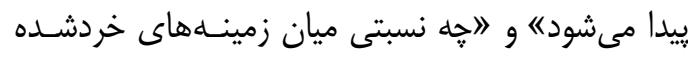
كره كند ده برقرار است؟ ي ييش رفته است. اين يزوهش از جهت شناخت بيشتر روابط رياضى حاكم

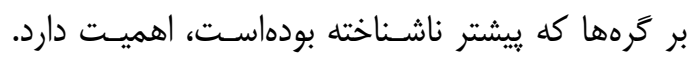

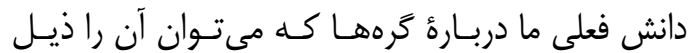

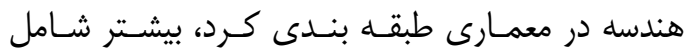

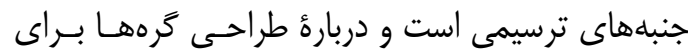

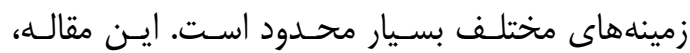

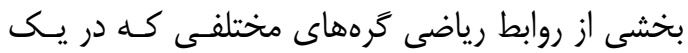

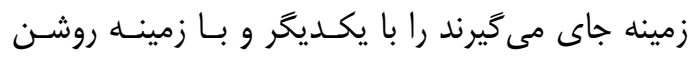

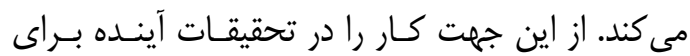

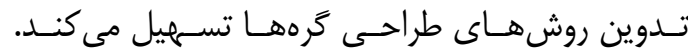
همجنين با توجه كهولت سن يا از دنيا رفتن بسيارى از استادكاران سنتى در سال هاى اخير كه فنون طراحئ

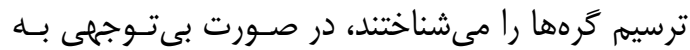

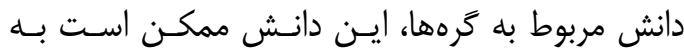

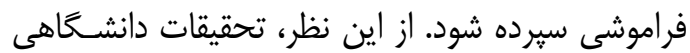
در اين زمينه ضرورى به نظر مىرسد. 
ساختارى آنها يرداخته است [10]. تحليلهاى رياضى

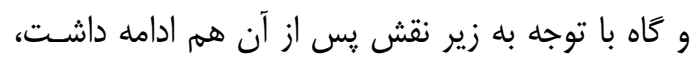

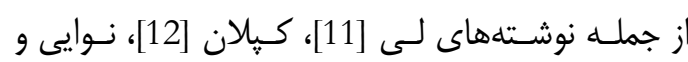

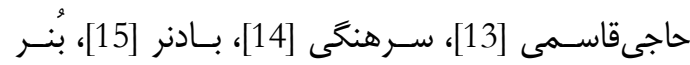

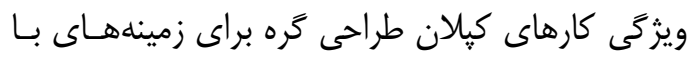

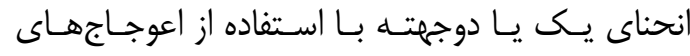
زيرنقش و همجنين استفاده از الكوريتمهاى كامبيوترى

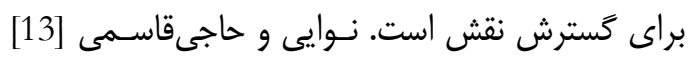

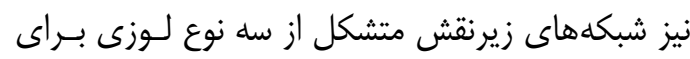

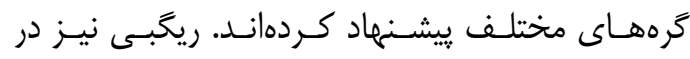

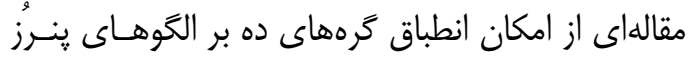

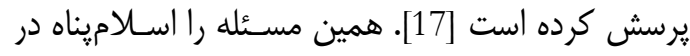

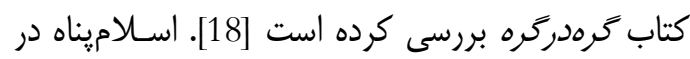

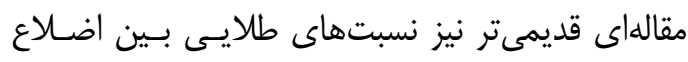

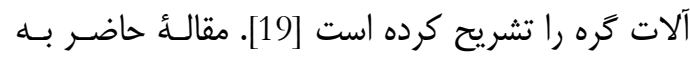

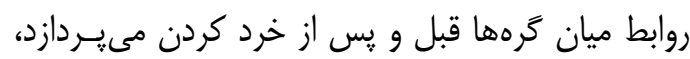

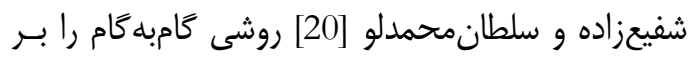
مبناى روش معرفى شده توسط شاكردان اسـتاد لـرزاده

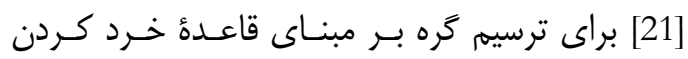
بررسى كردهاند. مهمترين تحقيق سالهاى اخير، مقالهاى است كـهـ در

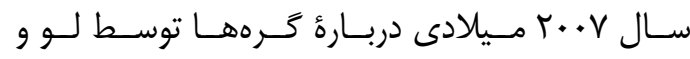

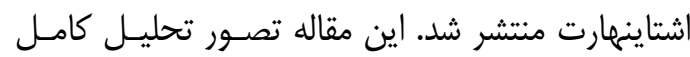

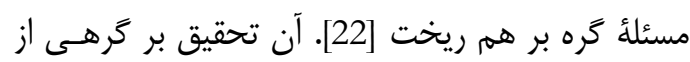

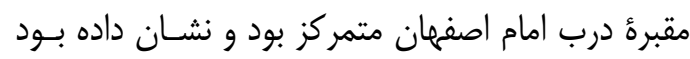
كه آن كره تقريباً به صورت كامل (در واقع به جز يازده

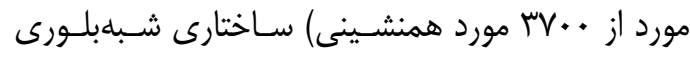

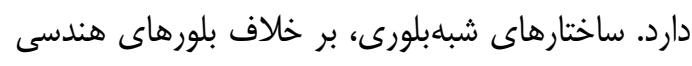

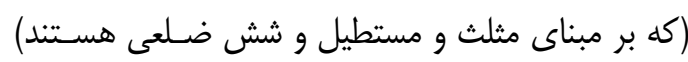

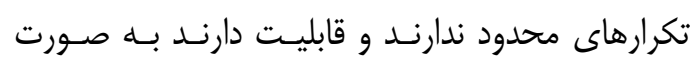

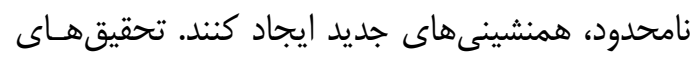

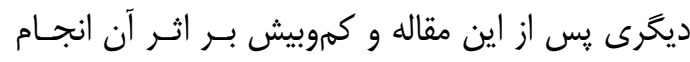

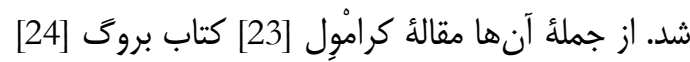

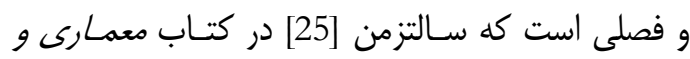

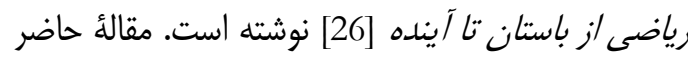

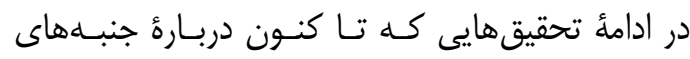

متون تحقيقى را هم با توجه به روشها و اهداف آنها مى توان به دستههاى مختلفى تقسيه كرد، با اين حـال

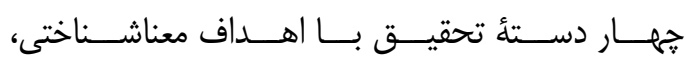

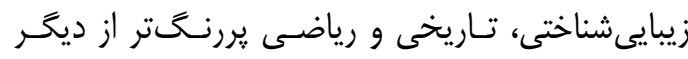

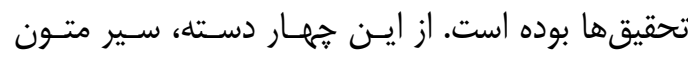

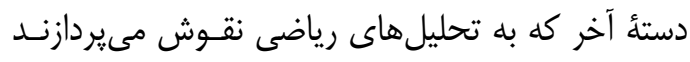

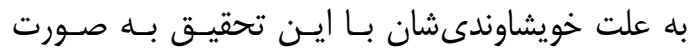
مشروحتر بررسى مى شود.

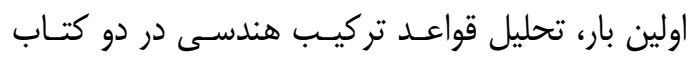

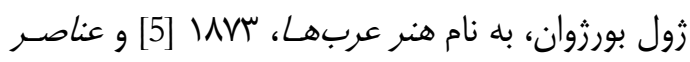

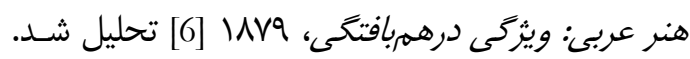

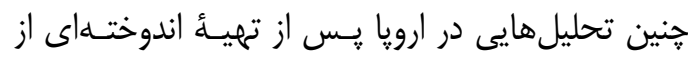

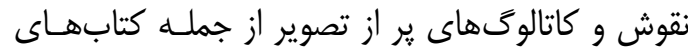
جونز [7] ممكن شده بود. بـورزوان سـه سـبك اصـلى تصلى

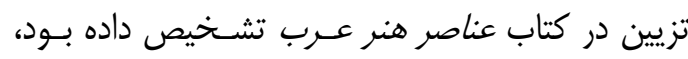

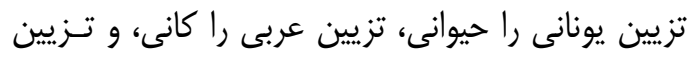

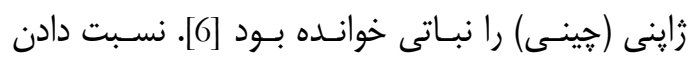

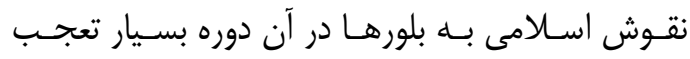

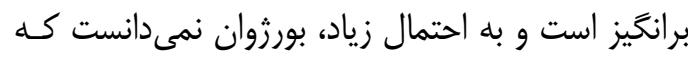

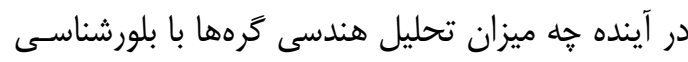

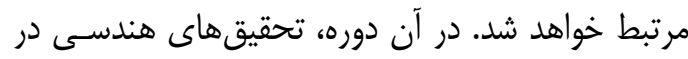

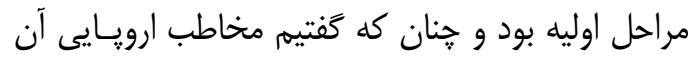

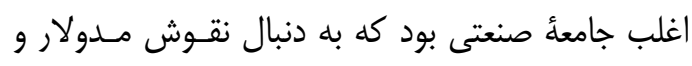
قابل تكرار مى گشت [8]

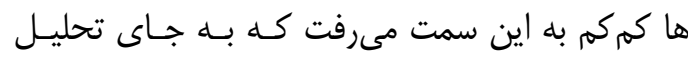

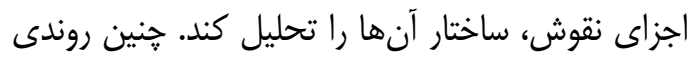

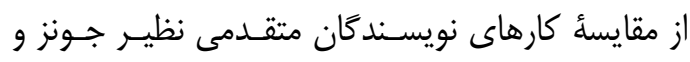

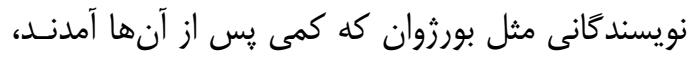
روشن مىشود. ادعاى جونز مبنى بر قواعد هندسى كرى

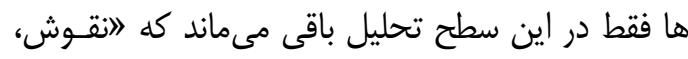

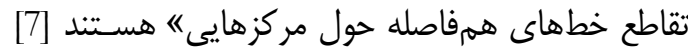

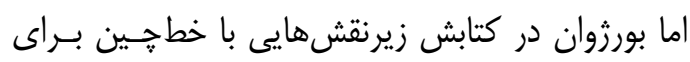

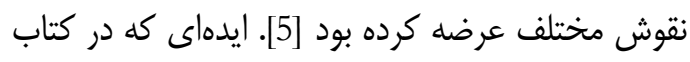

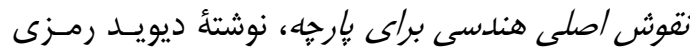

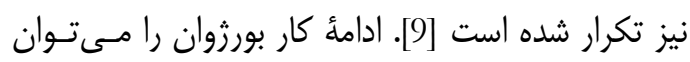

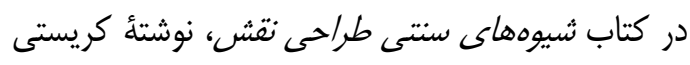

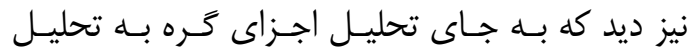


ضلعى را بيشتر، مربوط به شرق عالم اسلام و ايران مى

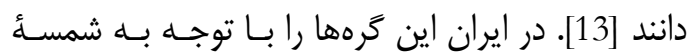
آنها "خره ده" مى خوانند. كَرها در منابع معاصرى كه استادكاران و شاگردانشان تدوين كردهاند، داراى جند قانون ساده هستند. اين كـه

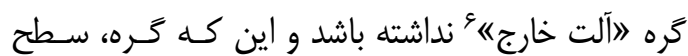
زمينه را به صورت كامل بيوشاند [21] و احر زمينـه بـا

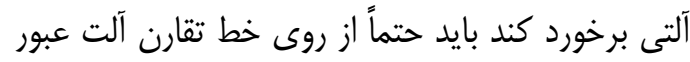

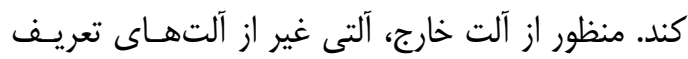

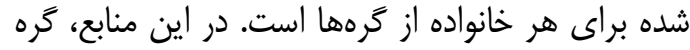

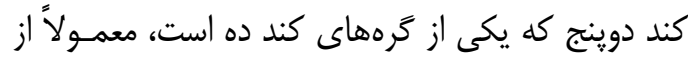

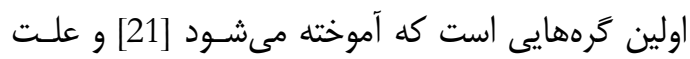

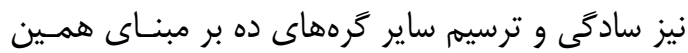

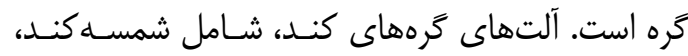
ترنج كند، ينج كند، طبل كند، و سرمهدان است (شكل () ).
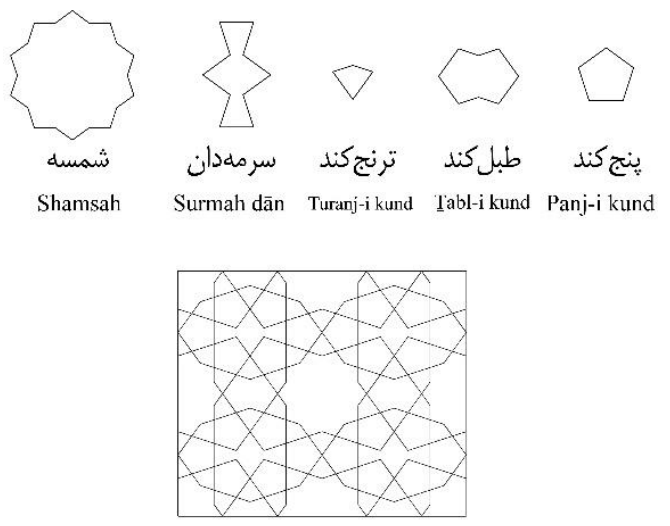

زمينهاى از "َره كند

$\Lambda$ rectangular frame of girih-i kund

شكل ا: آلتهاى كره كند و يك نمونه كره كند در زمينهاى

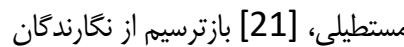

Fig. 1: Set of polygons of girih-i kund-i dah, [21] Redrawn by authors.

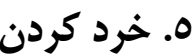

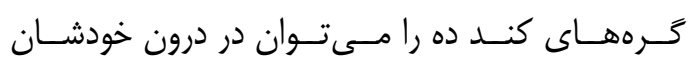

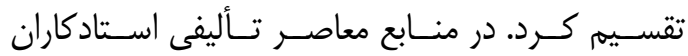

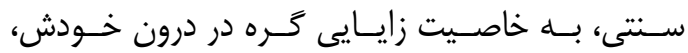

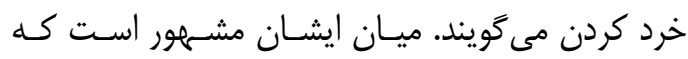

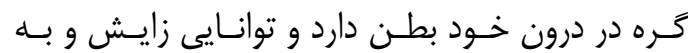

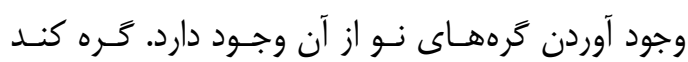

رياضى گرهها انجام شده است، قصد دارد روابط رياضى

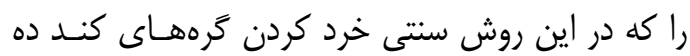

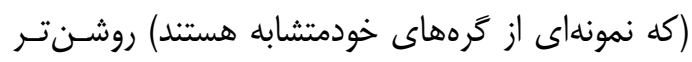
كند و راه را براى تحقيقات در تدوين روشهاى كائ كاملتر

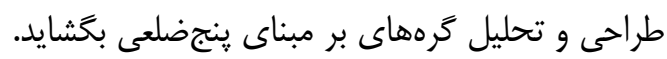

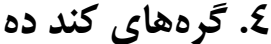

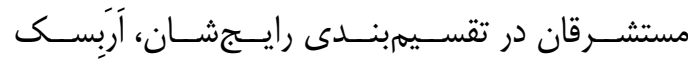
يا تزييناتى را كه در معمارى اسلامى بـــ (arabesque) كار مىرفت به سه دستأُ هندسى و كيـاهى و نوشـتارى (كتيبهاى) تقسيم مى كردند [8]. با وجود نقصهايى كـهـ در اين تقسيمبندى بود، تزيينات هندسى اسـلامى (يـاـيا

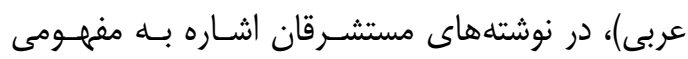
داشت كه در جهان ايرانى "كَره" مى خوانندش.ّ طـرح

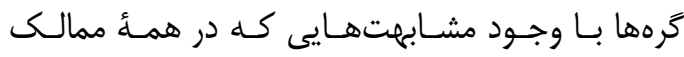
اسلامى دارند، كاملاً يكسان نيستند و برخى مستشرقان

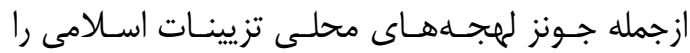

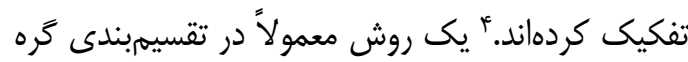
ها جه نزد مستشرقان، جاه در منابع بومى، تفكيك آنها

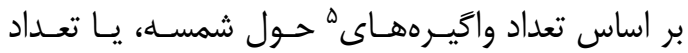
اضلاع جند ضلعى منتظمى است كه مبناى ترسيم گَره بوده باشد. به اين روش، كرههايى كه بر مبناى مثلث و ششضلعى بودند داراى شمسههاى شش يا نه يا دوازده

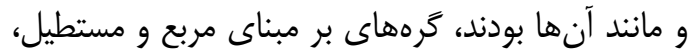

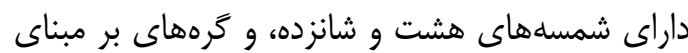
ينج، داراى شمسههاى ده بودنــــ شـكلهــاى مثلـث و و مستطيل و ششضلعى منتظه، شكلهايى هستند كه با

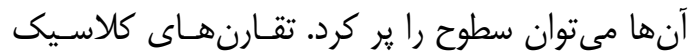

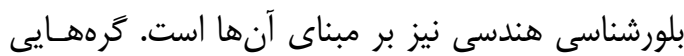

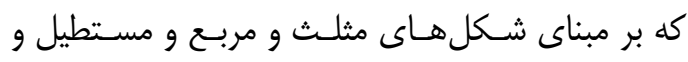

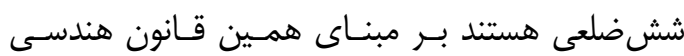

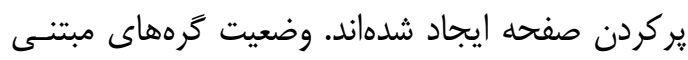
بر ينج ضلعى به كلى متفاوت است. ينج رضـلعى خاصـيت

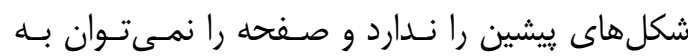
تنهايى با آن ير كـرد و از نظـر بلورشناسـى كلاسـيك،

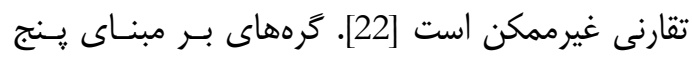


هندسـى اثبـات شــده اسـت [22] و هـهم بــه صـورت

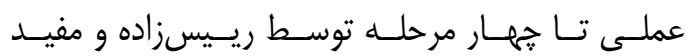
ترسيم شده است [21].
دوينج را به اين علت 》امالخـره| يـا مـادر ديخــر گـره

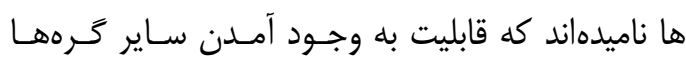

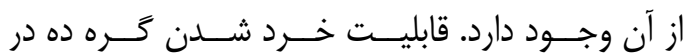
درون خودش (يعنى تقسـيم متـوالى) هـم بــه صـورت

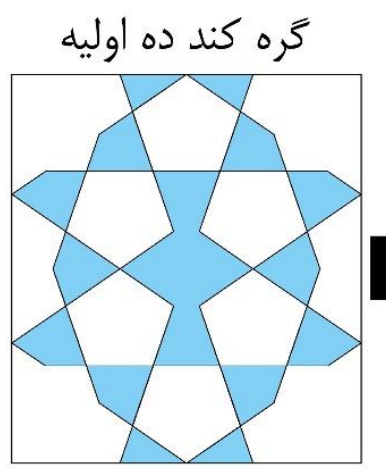

Frame before subdividing

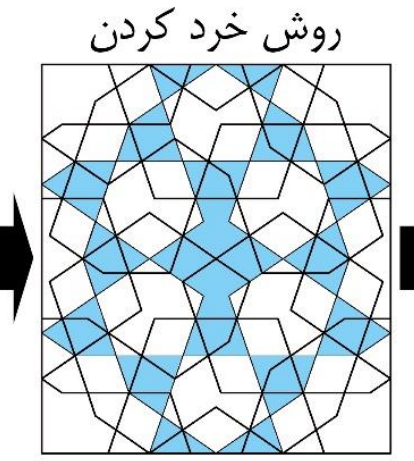

Method of subdividing

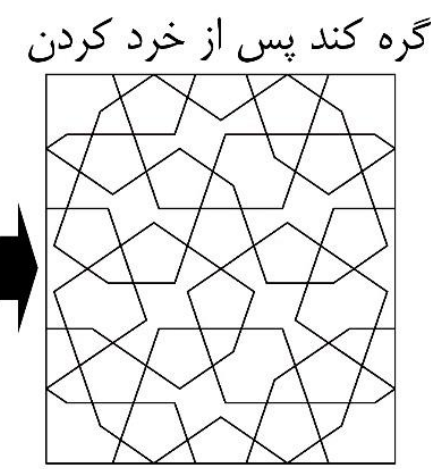

Frame after subdividing شكل r: گره كندى كه به روش تو حلقى به كره كند ريزترى خرد شده است.

Fig. 2: The subdividing method introduced by ustād Lurzādah

به ذهن مى آورد. هر جند امكان خردكردن، از نظر هندسى، به صورت نامتوالى و تا بىنهايت وجود دارد،

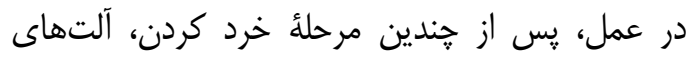
كره به حدى ريز مىشوند كه امكان اجرا با مصالح

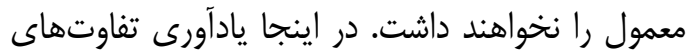

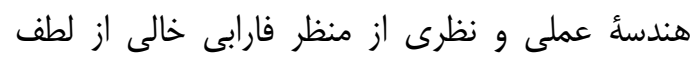
نيست [28]، و بر مبناى آن مى توان كفت، نكتهاى آنساى منقول از معماران سنتى دربارهٔ تعداد توالى خرد كردن، به هندسأ نظرى اشاره دارد.

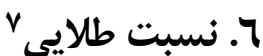

نسبت طلايى از اعداد كَنَ است. مقدار دقيق اين عدد

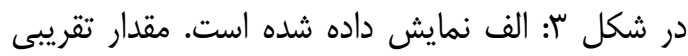

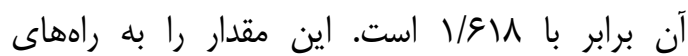

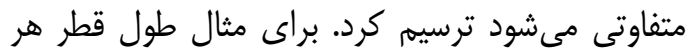

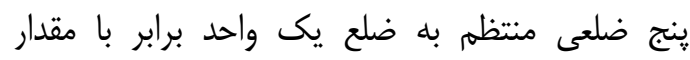
نسبت طلايى است (شكل و). معادلهاى كه در رابطأئ

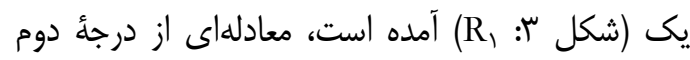

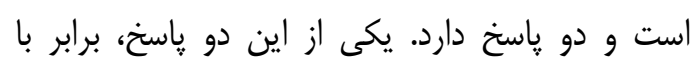

خُرد كردن گرمهاى با تقارنهاى كلاسيك بلورشناسانه،

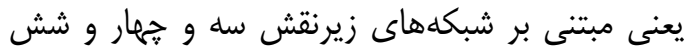

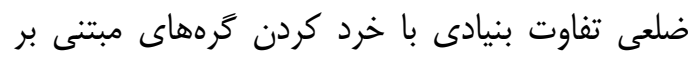

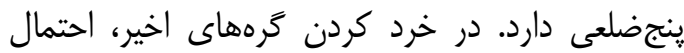
تغيير شبكأ زيرنقش نسبت به مقياس بزركتر كرها

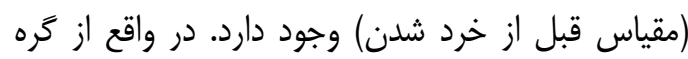

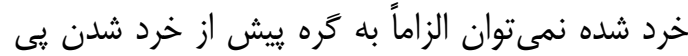
برد. فقدان ارتباط مستقيم در اين دو مقياس، سبب الزبان

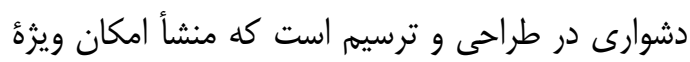
كرّهاى برمبناى ينج هم از همان است. تنوع بـىنهايت

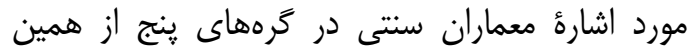

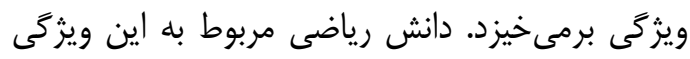

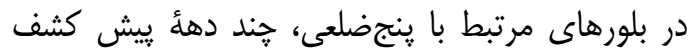

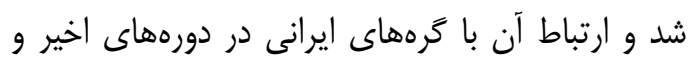

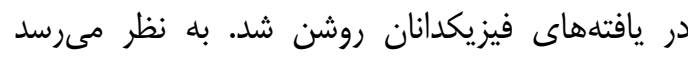
معماران سنتى با مفهوم بىنهايت بودن تعداد گرههاى

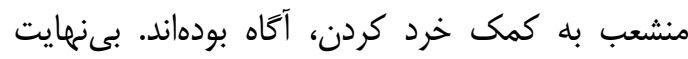
بودن تركيبات زيرنقشهاى خودمتشابه به صورد

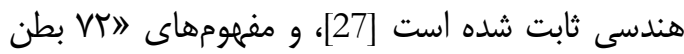

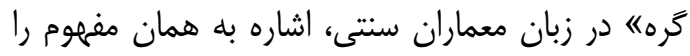


مىشود. در اين دنباله، مشاهده مىشود كه مقدار هر عضو برابر با مجموع دو عضو قبلى است. به عبارت

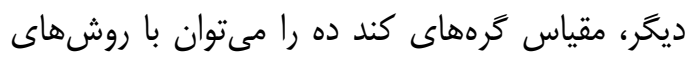

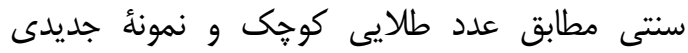
ترسيم كرد. در اين حالت، اندازهٔ زمينهها ثابت و مقياس

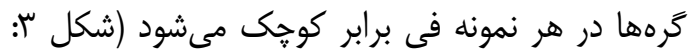
ب). حال اگر اندازه آلتهاى متناظر همأ كرهمهاى متوالى را يكى كنيم اين تغيير مقياس، اندازء زمينهُ

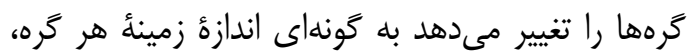
فى برابر اندازة زمينُٔ نمونهُ قبلى است (شكل سّا: ج). به

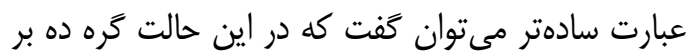
اساس نسبت طلايى در حال كَترش در زمينه است.

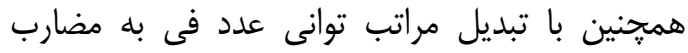

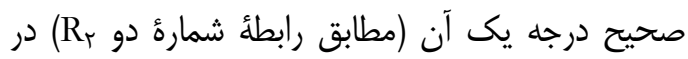
اندازٔ زمينهها، קنان كه ييدا است اندازئ هر ضلع زمينه در هر نمونه برابر با مجموع طول اضلاع نظير در دو

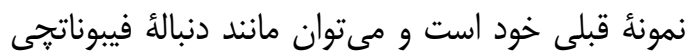
براى محاسبئ اندازه هر زمينه، از دو زمينأ قبلى استفاده

كرد (شكل ه).

\section{9. نمونه هاى شناسايى شده}

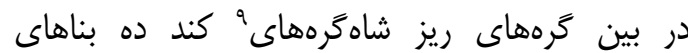
مختلف نيز مقياسهاى مختلفى وجود دارد. به اين

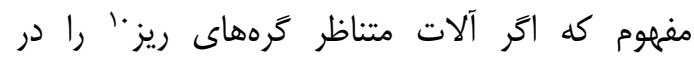
نمونههاى خرد شده، هم مقياس در نظر بخيريم آنغاه آلتهاى متناظر در كرههاى درشت آنها، كه حكم

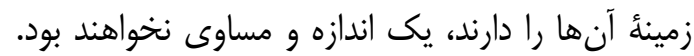
آلتهاى متناظر در كرههاى درشت، متناسب با اعضاى

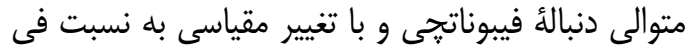
خواهند بود. براى نمايش اين مفهوم، بخشهائ دئ از

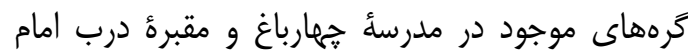
در كنار هم قرار گرفتند، طول زمينههاى آنها تصاعدى را تشكيل داد كه تا دو مرحله توسط نيخارندكان ادامه يافت. اين تصاعد را مىتوان تا هر تعداد ادامه داد
مقدار نسبت طلايى است. پِ توان دوم نسبت طلايى

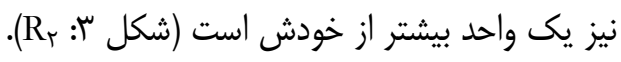

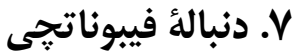
فيبوناتجى ^ اولين بار در اوايل ســــ سـيزدهم مـيلادى

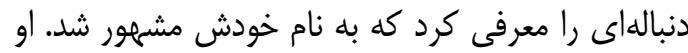
اين دنباله را در كتاب ليبرآباجي (Liber Abaci) و ذيـل كند

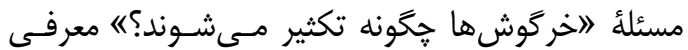

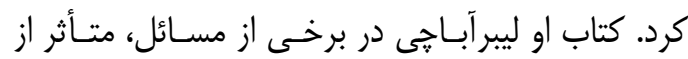
خوارزمى و همجنين ابوكامل، رياضيدان مصرى استـا

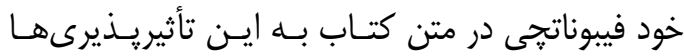
اشاره نكرده است [29]. در اين دنباله نحوهُ تكثير شدن جفت خر گوشها محاسبه مىشد. تعداد جفت خر خـوش

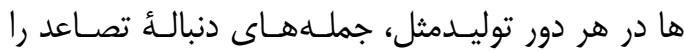

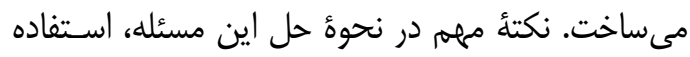
از مقدار اعضاى قبلى در محاسبئ عضو جديد بود [30].

\section{^. اثبات وجود دنبالهُ فيبوناتجى در طول زمينهُ در خردكردن متوالى تره كند ده}

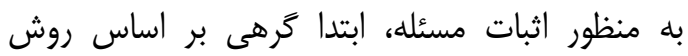

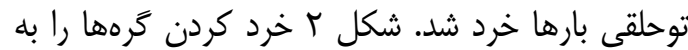
روش توحلقى نشان مىدهد كه در كره محصول، معادل كند آلتها در نظر كَفته شده است. در خرد كردن به روش توحلقى نسبت ميان اندازء آلات نظير (براى مثال طول ضلع קنج ضلعىها) در كره ثانويه

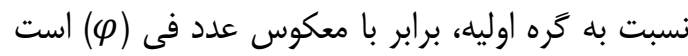
(شكل "ّ: ب). اخر كَرهاى ريز تمام زمينهها هم مقياس شوند آنكاه اين تصاعد در اندازه زمينهها منعكس مىشود به كَونهاى كه اندازه هر زمينه نسبت انداه به زمينة قبلىاش فى برابر مىشود (شكل سّا: ج). در

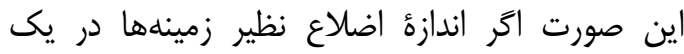
توالى نوشته و اندازء عضو اول يك واحد در نظر ترَفتها شود، دنبالهاى هندسى با قدر نسبت عدد فى تشكيل

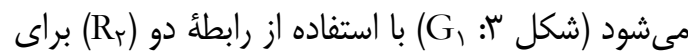

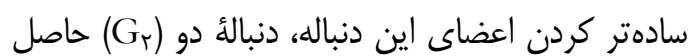




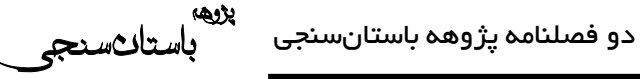

A:

الف:

Golden ratio is equal to $\frac{1+\sqrt{5}}{2}$

نسبت طلايى برابر با

Equation one $R_{1} x^{r}=x+1 \Rightarrow x=\left(\frac{(\sqrt{\Delta}+1)}{r} \cdot \frac{(\sqrt{\Delta}-1)}{r}\right)$ رابطُ شمارة يك

Equation two $R_{r} \quad \boldsymbol{\phi}=\frac{(\sqrt{\Delta}+1)}{r} \Rightarrow \boldsymbol{\phi}^{r}=\boldsymbol{\phi}+1 \quad$ رابطة شمارة دو

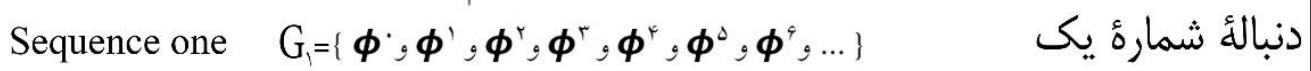

Sequence two $G_{r}=\{1, \boldsymbol{\phi}, \boldsymbol{\phi}+1, r \boldsymbol{\phi}+1, r \boldsymbol{\phi}+r, \Delta \boldsymbol{\phi}+r, \wedge \boldsymbol{\phi}+\Delta, \ldots\}$ دنبالة شمارة دو,

B:

ب:

1
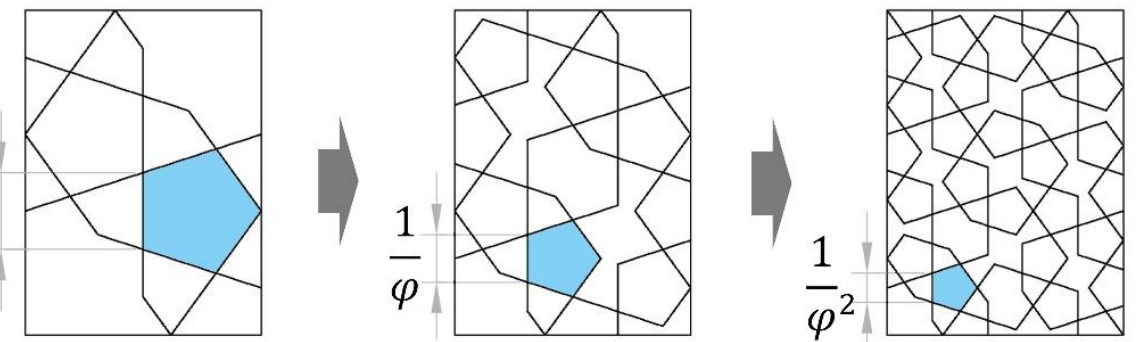

C:

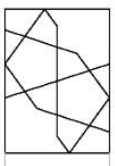

1

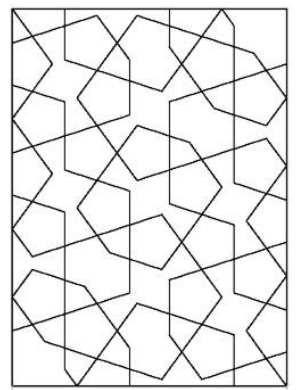

$\varphi^{2}$

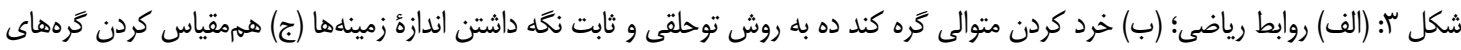
ريز زمينهها و انعكاس تغييرات در اندازه زمينهها

Fig. 3: A) Mathematical equations B) Subdividing and maintaining frame dimensions C) Subdividing and maintaining polygon dimensions. 


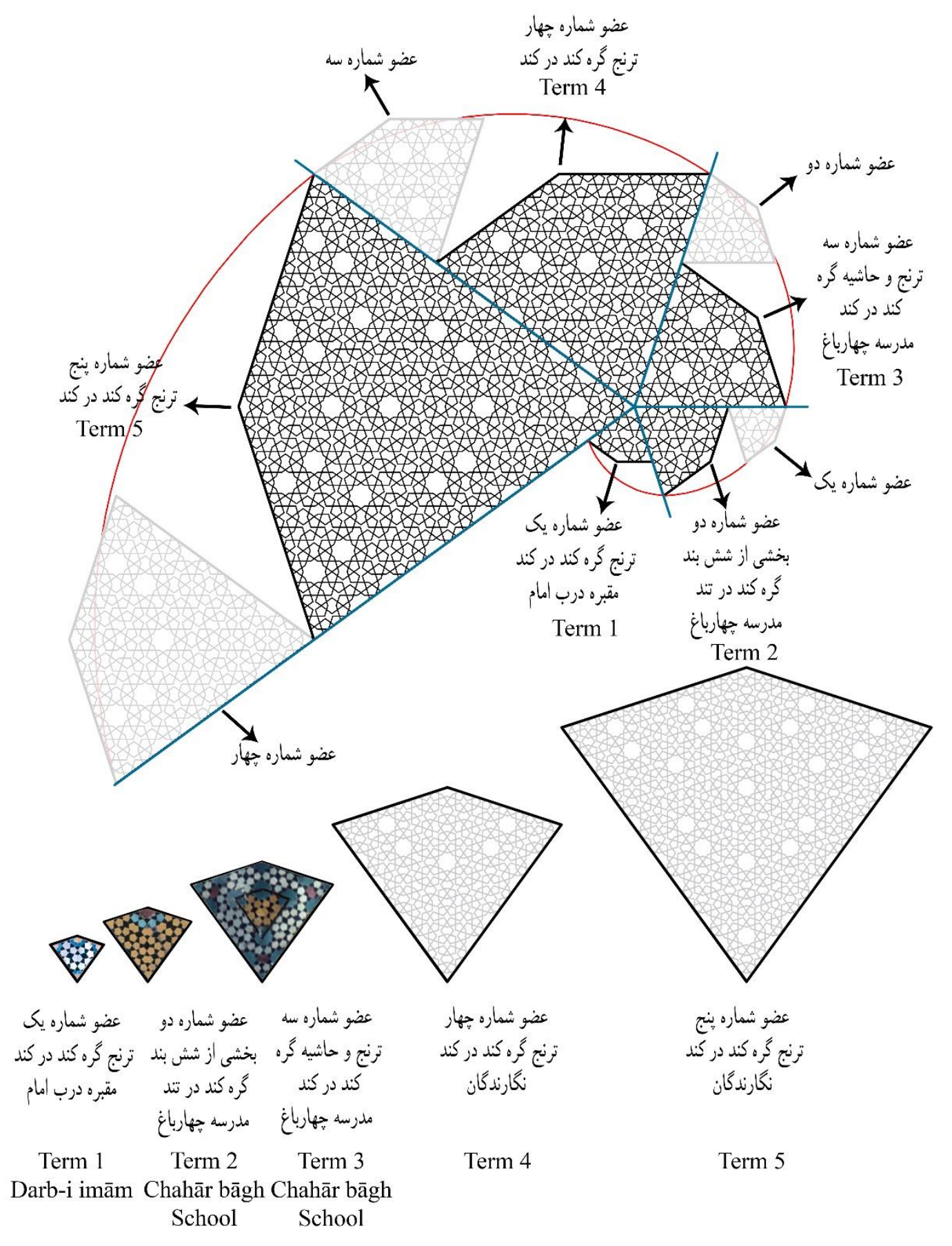

شكل f: نمونههايى از ترنج در گرمهاى موجود در بناهاى تاريخى كه زمينههاى آنها در ماريبج تعميم فيبوناتجى قرار مى گيرد.

Fig. 4: Real world samples of kite polygons arranged in generalization of Fibonacci sequence and extended by authors. 


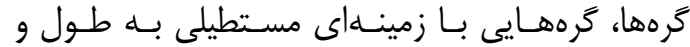
عرضى با همين نسبت انتخاب شد و تـوالى فيبونـاتجي

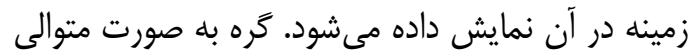

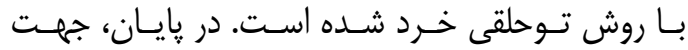
سهولت در نمايش دنباله فيبوناتجى در توالى اندازء كره

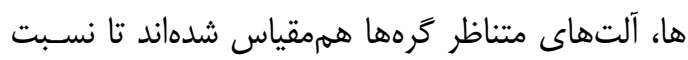
مورد نظر در اندازهٔ زمينهها منعكس شود. مستطيل هاى

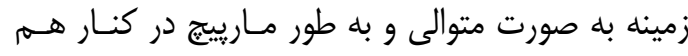

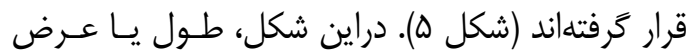

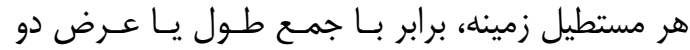
مستطيل كوجكتر از خودش است. براى مثال، مجمـوع

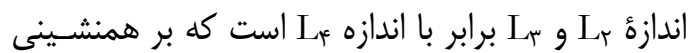

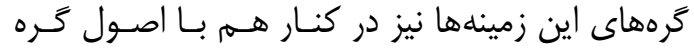

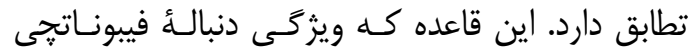
است براى زمينههاى ديگر نيز صادق است.
جنان كه در مطالب ييشين ذكر شد، محصول خرد كردن متوالى كَه كند ده به روشى كه استاد لرزاده

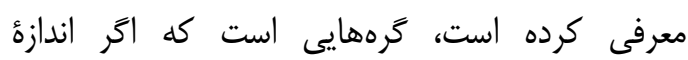
آلتهايشان را ثابت نكَه داريم طول زمينههاى آنها درائ

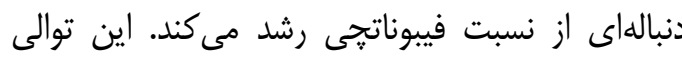
طولها همجنين تصاعدى هندسى مىسازد كه نسبت جملههاى متوالى آن به هم برابر عدد فى يا نسبت هيت

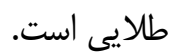

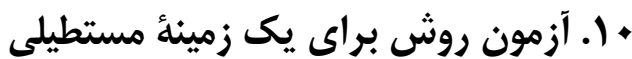

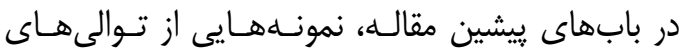

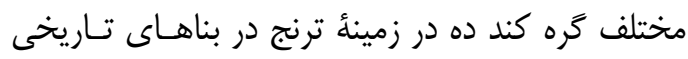

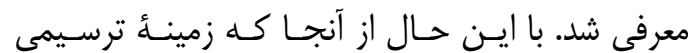

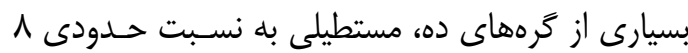

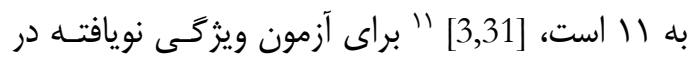

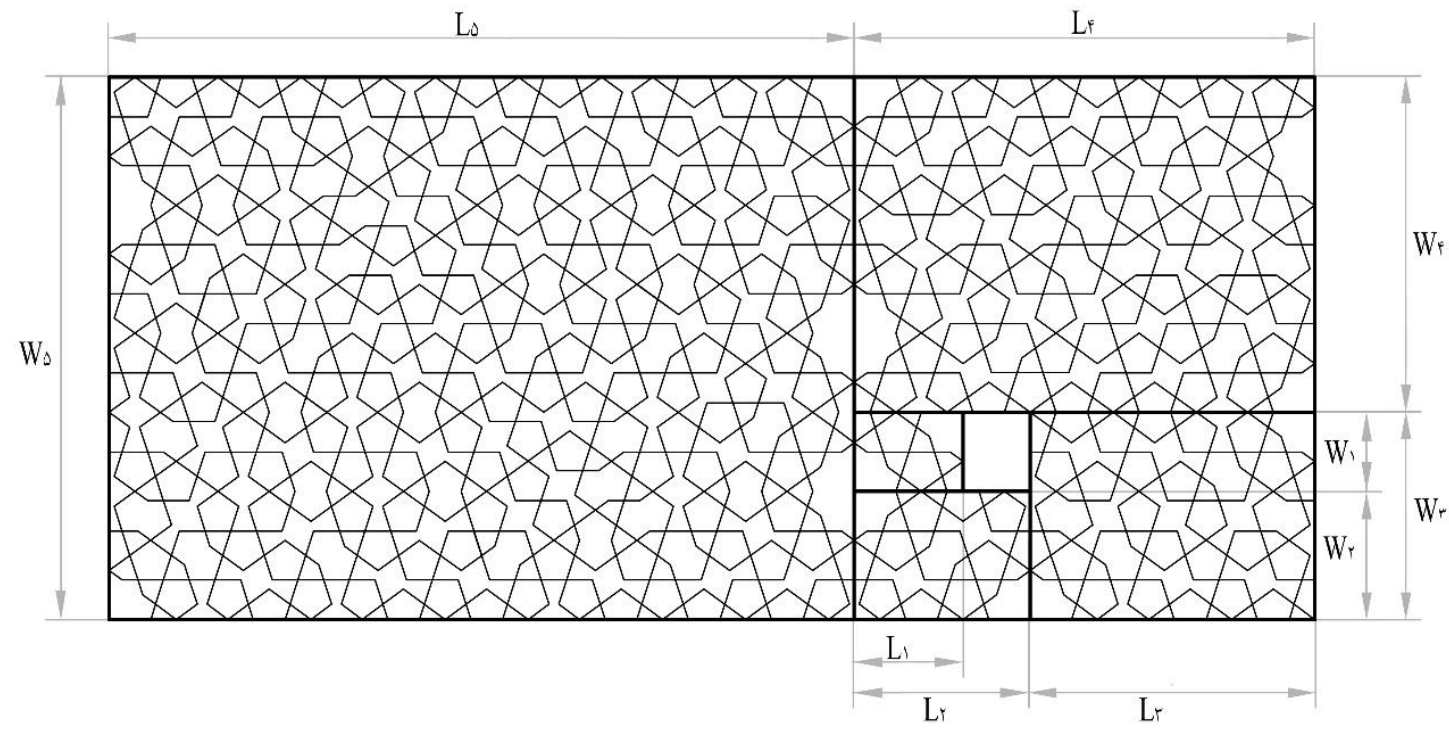

شكل ه: وجود رابطة تعميم فييوناتجى ميان طول و عرض در يك نمونه زمينة مستطيلى

Fig. 5: Generalization of Fibonacci in widths and lengths of rectangular frame

زمينه يكسان باقى مىماند. به كمك يافتههاى اين تحقيق مىتوان از روى يك گره كند ده ترسيه شده

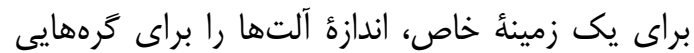
به مقياسهاى خردتر كه در آن زمينه قابل ترسيه

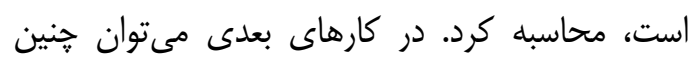

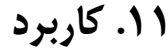

يكى از دشوارىها در تحليل هندسى كرهها و طراحى

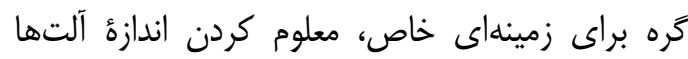
است. در گرههايى كه دست كردان نيستند و از قواعد هندسى تبعيت مى كنند، اندازه آلتهاى متناظر در كل ديست 

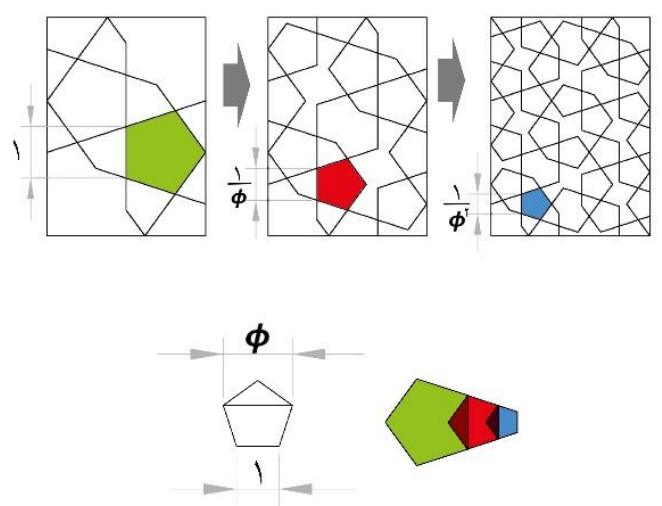

شكل و: تناسب آلتهاى ينج در خرد شدن متوالى :

Fig. 6: Scale factor of pentagons in repeatedly subdividing

در مقاله، نشان داده شد از آنجا كه گرمهاى ده بر

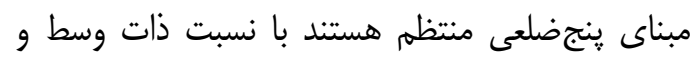
طرفين ارتباط دارند. اين نسبت، سبب به ونئ وجود آمدن

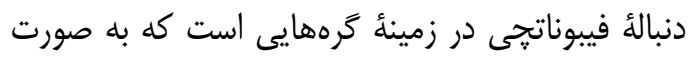

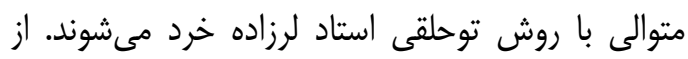

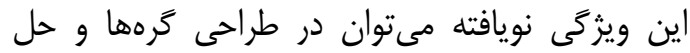

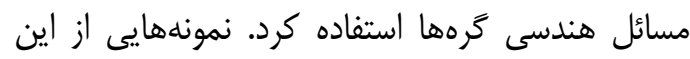
كرهها را در آثار تاريخى نشان داديم كه مىتوان اجزاى لهائ

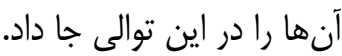

\section{" ا. نتيجلكيرى}

كره كند ده يكى از خانوادههاى گرمهاى ايرانى است

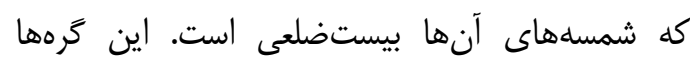

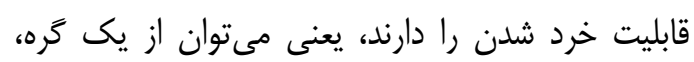

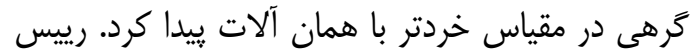

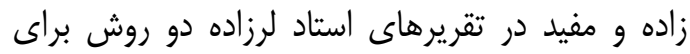
خرد كردن گرمهاى كند ده معرفى كردهاند. در روش جامعتر (روش توحلقى) همأ نتايجى كه از روش ديخر

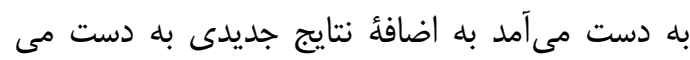

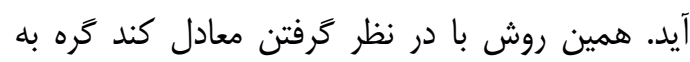
دست آمده از آن، مبناى محاسبات اين مقائ داله

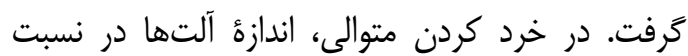

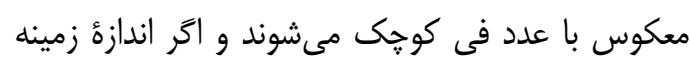
هاى متوالى را به نحوى بزرى كنيم كه اندازئ آلتهاى
محاسبههايى را پايئ حل مسئلة كَه به كمك الكَوريتم هاى رايانهاى براى زمينههاى مسطح و منحنى قرارداد.

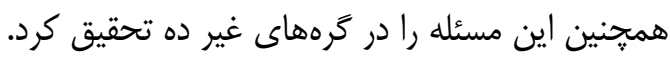

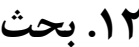

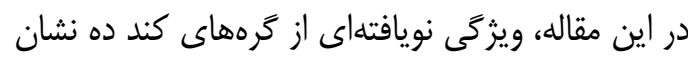

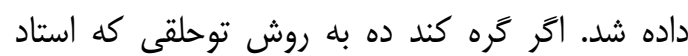

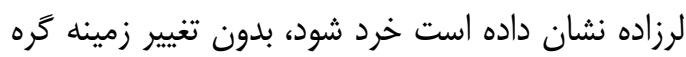

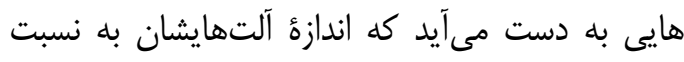
ذات وسط و طرفين (يا نسبت طايى) كوخى

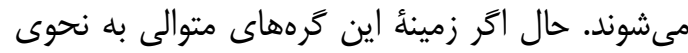

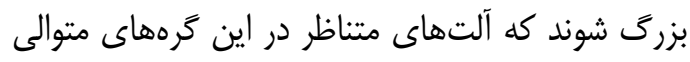
هماندازه شوند، طول و عرض اندازه زمينهها در دنباله

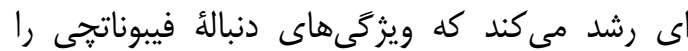

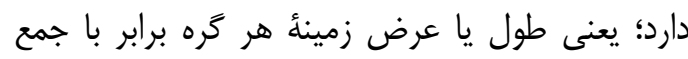
طول يا عرض زمينههاى دو گره قبل از خودش است،

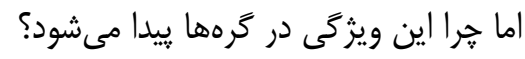

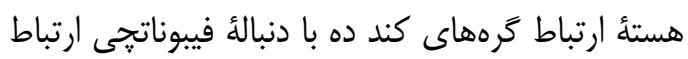
آنها با نسبت ذات وسط و طرفين است، و علت ارتباط آنها با اين نسبت ارتباطشان با ينج ضلعى منتظم است.

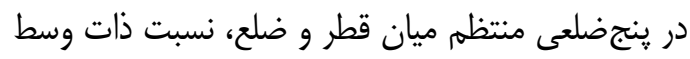
و طرفين برقرار است. در خرد كردن متوالى كره كند دهان نيز (با ثابت نحكه داشتن اندازء زمينه) آلتهاى ينج (كرد

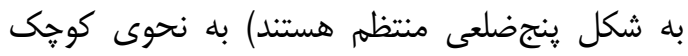

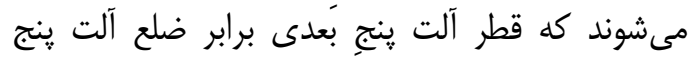
قبلى است (شكل 9). در نتيجأ رابطؤ رياضى شمارئ دو

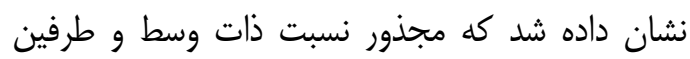
برابر يك واحد بيش از نسبت ذات وسط و طرفين است. با ثابت نغاه داشتن اندازه آلتها، اندازهُ زمينه در نسبت مستقيم با دنبالهاى از توانهاى صحيح نسبت ذات وسط و طرفين رشد مى كند (شكل سّ: (G)). اين

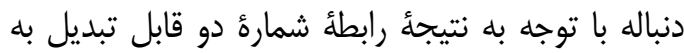

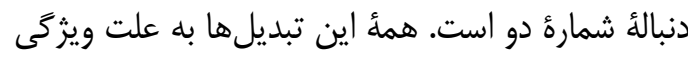
نسبت ذات وسط و طرفين ممكن بود. جنان كه در دنباله شماره دو مشخص است هر جمله برابر با جمع دمات دو جملة يِيشين خود است. 


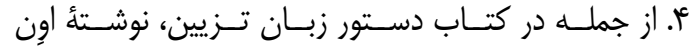

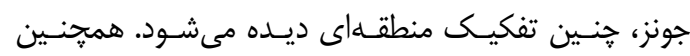

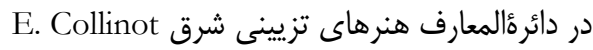

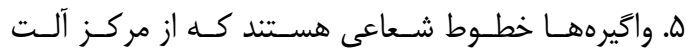

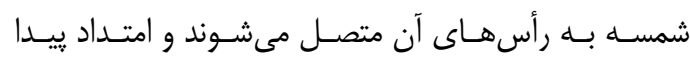

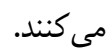

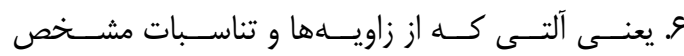

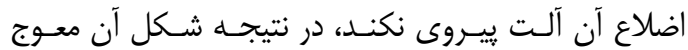

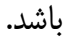
V.نويسـندكان مقالـه از آقـاى روح الله مجتهــــاده بـــراى

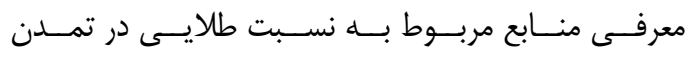
اسلامى تشكر مى كنند.

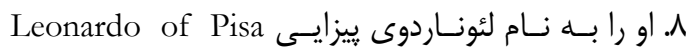
نيز مىشناسند.

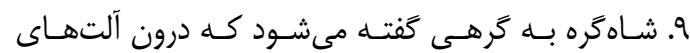

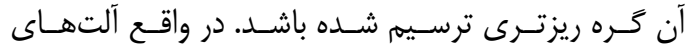

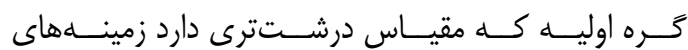
كرهماى ريزتر باشد.

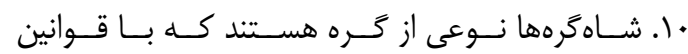

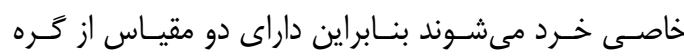

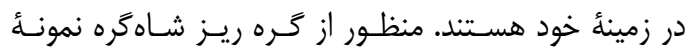
خرد شدة ترسيم شده در كره اوليه است.

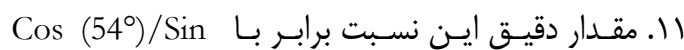

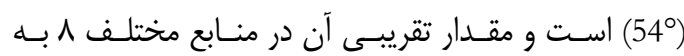

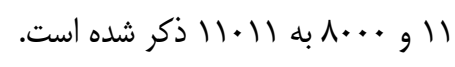

\section{References}

[1] Lurzādah Husayn. Reviving Forgotten Arts, Vol 1. Tehran: Author, 1358. [in Persian] [لرزاده حسين. احياى هنرهاى از ياد رفته، مجلــ اول.

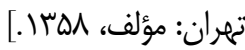

[2] Sha rbāf Aṣghar. Geometric Arabesque and Ribbed Vaults. Tehran: Iranian Cultural Heritage Organization, 1361. [in Persian]

[شعرباف اصغر. كره و كاربندى. تهران: سازمان ميراث

$$
\text { فرهنكى، [اعسا. }
$$

[3] Zumarshìdī Husayn. Girih Tilings in Architecture and Handicrafts. Tehran: Center for University Publishing, 1365. [in Persian]

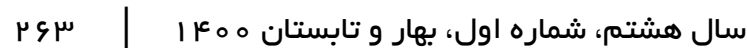

متناظر در كرهها يكسان باشد، طول اعضاى متناظر زمينهها مطابق دنباله فيبوناتجى رشد مى كند، به نحوى بـان

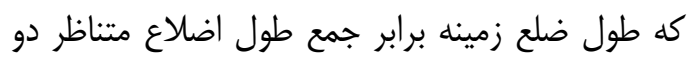

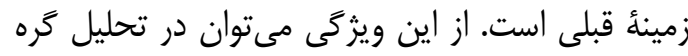

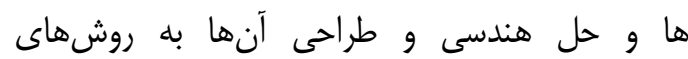

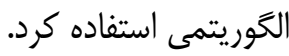

\section{سياسگَز ارى}

نويسندكان مقاله از آقـاى روحالله مجتهـــاده اسـتاديار

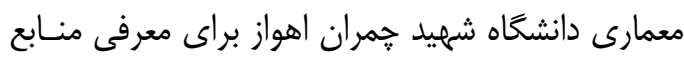

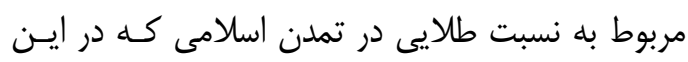

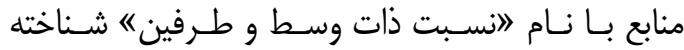
مى شده است تشكر به جاى مى آوردند.

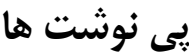

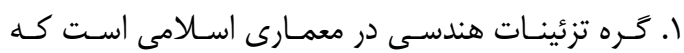
از قراركرفتن تجندضلعىهاى بسـته (بـهـ نـام آلـت) در كنـار هم و يركردن سطح تشكيل شده است.

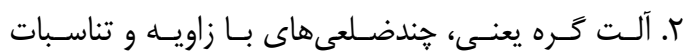

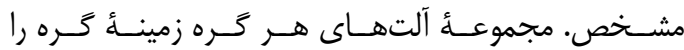

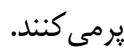

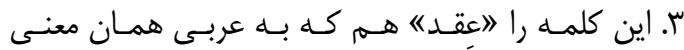
كره را مى دهد مىخوانند.

[زمرشيدى حسين. كره جينى در معمارى اسلامى و هنرهاى

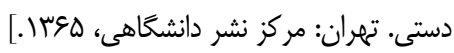

[4] Māhīr al-Naqsh Mahmūd. Design and Execution of Tiling in Iran: Islamic Period. Tehran: Reza Abbasi Museum, 1361. [in Persian]

[ماهر النقش محمود. طرح و اجراى نقش در كاشيكارى

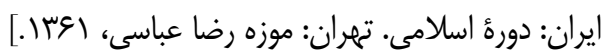

[5] Bourgoin Jules. Les Arts Arabes. Paris: A. Morel, 1867.

[6] Bourgoin Jules. Les Éléments de l'Art Arabe. Paris: Librairie de Firmin-Didot et cie, 1879. p.24, 82.

[7] Jones Owen. The Grammar of Ornament by Owen Jones: Illustrated by Examples from Various Styles of Ornament. Day 
and Son, 1865. p.74,

[8] Necipoğlu Gülru. The Topkapi Scroll: Geometry and Ornament in Islamic Architecture. California: Getty Center for the History of Art and the Humanities, 1995. p. 61,62.

[9] Hay David R. Original Geometrical Diaper Designs. London: D. Bogue 1849.

[10] Christie Archibald H. Traditional Methods of Pattern Designing; an Introduction to the Study of the Decorative Art. Oxford: Clarendon press.1910.

[11] Lee Anthony J. Islamic Star Patterns. Muqarnas 1987; 4: 182-197.

[12] Kaplan Craig S. Islamic Star Patterns from Polygons in Contact. In: Proceedings of Graphics Interface 2005. Canadian Human-Computer Communications Society, p. 177-185.

[13] Navāyī Kāmbīz, Kāmbīz Hājīqasemī. Khesht-o Khiāl: An Interpretation of Iranian Islamic Architecture. Tehran: Shahid Beheshti University, Soroush, 1390. p.196. [in Persian]

[نوايى كامبيز، كـامبيز حاجىقاسـمى. خشـت و خيـال:

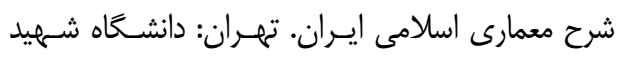

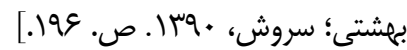

[14] Sarhangi Reza. Interlocking Star Polygons in Persian Architecture: The Special Case of the Decagram in mosaic Designs. Nexus Network Journal 2012; 1-28. DOI. 10.1007/s00004-012-0117-5.

[15] Bodner BL. From Sultaniyeh to Tashkent Scrolls: Euclidean Constructions of Two Nine-and Twelve-pointed Interlocking star Polygon Designs. Nexus Network Journal 2012; 14: 307-332.

[16] Bonner Jay F. The Historical Significance of the Geometric Designs in the Northeast Dome Chamber of the Friday Mosque at Isfahan. Nexus Network Journal 2016; 18: 55-103.

[17] Rigby John. Creating Penrose-Type Islamic Interlacing Patterns. Proc Bridges: Mathematical Connections in Art, Music and Science,(London, 2006), eds R Sarhangi and J Sharp 2006; 41-48.

[18] Islām Panāh Muḥammad Husayn. Poetic Explanation of Self-Similar Geometric Arabesque. Kerman: Author, 1396 [in Persian]

$$
\begin{aligned}
& \text { [اسلاميناه محمدحسين. شـرح منظومـهـ گــره در گَـره. } \\
& \text { كرمان: محمدحسين اسلاميناه، عوسا. }
\end{aligned}
$$

[19] Islām Panāh Muḥammad Ḥusayn. Notes on Drafting Geometric Arabesque. Culture of Iranian Land, Vol 30. 1384; 355-360. [in Persian]

$$
\begin{aligned}
& \text { [اسلاميناه محمدحسين. تكملهاى بر رسم گره. فرهنى }
\end{aligned}
$$

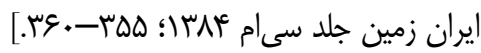

[20] Shafizade Asadolah, Saiede Soltan Mohammadlo. Presentation of the Step by Step Model of Knot Drawing Method Based on the Principle of Grinding (Generative). Negareh 1399; 54: 77-94. DOI. 10.22070/negareh.2020.1239 [Original Text in Persian with English Abstract]

[شفيعزاده اسدالله، سـعيده ســلطان محمدلو. ارائــ مـدل

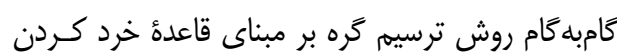

(زايندگى). نخره وq

[21] Ra'īszādah Mahnāz, Husayn Mufīd. Reviving Forgotten Arts: Fundamentals of Traditional Architecture in Iran According to Ustad Husayn Lurzādah. Tehran: Mola (Mawlá), 1374. p.141-148. [in Persian]

$$
\begin{aligned}
& \text { ] ريـيسزاده مهنــاز، حسـين مفيـد. احيـاى هنرهـاى از }
\end{aligned}
$$

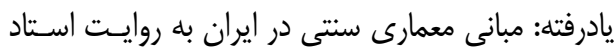

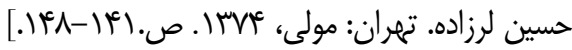

[22] Lu Peter J, Peter J Steinhardt. Decagonal and Quasi-Crystalline Tilings in Medieval Islamic Architecture. Science 2007; 315: 1106-1110.

DOI. 10.1126/science.1135491 p.1107.

[23] Cromwell Peter R. The Search for QuasiPeriodicity in Islamic 5-Fold Ornament. The Mathematical Intelligencer 2009; 31 (1): 36-56. DOI. 10.1007/s00283-0089018-6.

[24] Broug Eric. Islamic Geometric Design. London: Thames \& Hudson, 2013.

[25] Saltzman Peter. Quasi-Periodicity in Islamic Geometric Design. In: Williams K, Ostwald MJ (eds) Architecture and Mathematics from Antiquity to the Future: Volume I: Antiquity to the 1500s. New York: Birkhäuser, p. 585-602. DOI: 10.1007/978-3-319-00137-1_39.

[26]Ostwald MJ, Williams K (eds). Architecture and Mathematics from Antiquity to the Future: Volume I: Antiquity to the 1500s. 1st ed. 2015. New 
York: Birkhäuser, 2015.

[27]Levine Dov, Steinhardt Paul J. Quasicrystals. I. Definition and structure. Physical Review B 1986; 34: 596-616. p .609. DOI 10.1103/PhysRevB.34.596.

[28] Fārābī Muḥammad ibn Muḥammad. Encyclopedia of the Sciences. Beirut: Dār va Maktabat al-Hilāl. 1996. p.51 [in Arabic]

$$
\text { [فارابى محمد بن محمد. احصـاء العلـوم. بيـروت: دار و }
$$

$$
\text { مكتبه المهلال. }
$$

[29] Allard André. The Influence of Arabic Mathematics in the Medieval West. Roshdi Rashed (éd), Encyclopedia of the History of Arabic Science 1996; 3: 539_ 80.

[30] Stakhov Alexey P. The Golden Section in the Measurement Theory. Computers \&
Mathematics with Applications 1989; 17 (4-6): 613-638. DOI. 10.1016/08981221(89)90252-6 p.616.

[31] Valibeig Nima, Nooshin Nazarieh, Sanaz Rahravi. Comparing Study of Mother Girih in the Drawing Methods Domain, with Offering an Unwrtiten Method. Journal for the History of Science 1396; 15: 251-274.

DOI.

10.22059/jihs.2019.237807.371406

[Original Text in Persian with English Abstract]

[ولى بيخ نيما، نوشين نظريه، سـاناز رهــروى. مطالعـــ

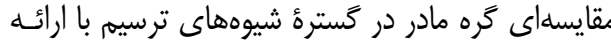

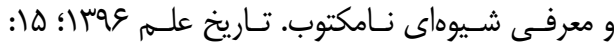

$[r R i-r a]$ 